Interdyscyplinarny charakter badań językowych, red. J. Małocha, Kraków 2017, s. 81-91

DOI: http://dx.doi.org/10.15633/9788374386081.05

\title{
Bożena Tuszewska
}

\section{Praeclarum est Latine et Graece scire. Warto uczyć się języków klasycznych!}

Rzeczą wiadomą jest, że języki klasyczne są pomocne w wielu dziedzinach nauki (m.in. w filozofii, teologii, prawie, biologii, medycynie). Niewątpliwie ich znajomość ułatwia również przyswajanie języków nowożytnych (np. łac. lectio to pol. lekcja, wł. lezione, hiszp. leccion, ang. lesson, niem. Lektion, franc. leçon) oraz pomaga w zrozumieniu wielu obcych terminów bez konieczności sięgania do słownika. Za sprawą jasnych reguł gramatycznych, które wymuszają precyzję tłumaczenia, łacina i greka uczą zasad logicznego myślenia; a w związku z tym pomagają także w formułowaniu wypowiedzi w języku ojczystym, dzięki znajomości etymologii słów i analizie gramatycznej. Ci wreszcie, którzy czytają w oryginale teksty starożytnych Greków i Rzymian, mają możliwość niejako bezpośredniego obcowania $\mathrm{z}$ wartościami etycznymi antycznego świata, które stanowią zarazem fundament naszej cywilizacji ${ }^{1}$.

Wypunktowane powyżej nieprzemijające walory języków klasycznych zostały szerzej przedstawione i zegzemplifikowane w toku niniejszego artykułu, zaś w końcowym jego fragmencie przytoczono przykłady inicjatyw - publikacji, konferencji, zjawisk z zakresu kultury masowej - które unaoczniają ciągłą obecność języków antycznych w przestrzeni współczesnej kultury wysokiej i niskiej.

1 Zob. M. Herman, O łacinie tylko dobrze. De lingua Latina nil nisi bene. Język łaciński i grecko-łacińskie dziedzictwo kulturowe we współczesnej Europie, Kraków 2014, s. 231n. 


\section{Kod kulturowy}

Prawdą jest, że nauka języków klasycznych wymaga dużo wysiłku i czasu, a efekty - przynajmniej na początku - wydają się znikome. Musimy jednak pamiętać, że kultury łacińska i grecka to fundament naszej cywilizacji. Stanowią one bazę kulturową i tworzą pewien rodzaj kodu, który łączy pokolenia. To poczucie wspólnoty cywilizacyjnej daje człowiekowi wiedza humanistyczna ${ }^{2}$.

Można oczywiście „CV” czytać po angielsku jako „si vi” i nie wiedzieć, że to łacińskie curriculum vitae („bieg życia”), czy odbierając pocztę elektroniczną nie zdawać sobie sprawy z tego, co znaczy skrót „a.m./p.m.” (ante/post meridiem - „przed południem/po południu”), lub wykonując ćwiczenie z języka obcego, nie rozumieć znaczenia skrótu „e.g." (łac. exempli gratia - „na przykład”, „użyty we wzorcowym przykładzie").

Często nawet nie zdajemy sobie sprawy z posiadanej przez nas wiedzy lingwistycznej. Być może więc wpadlibyśmy w panikę zapytani, jak po lacinie jest „dwa razy”, „za darmo”, „1 kwietnia”, „po napisaniu”, „zmartwychwstał", mimo że rozumiemy zwroty bis, gratis, prima Aprilis, post scriptum, resurrexit.

\section{Klasyczne pochodzenie wielu polskich słów}

Niejednokrotnie używamy imion łacińskich (Beata, Klara, Marcin, Marek, Paweł, Wiktoria) czy też greckich, które dotarły do nas dzięki łacinie (Agata, Barbara, Irena, Jacek, Krzysztof, Zofia), jednak nawet osoby je noszące często nie są świadome ich znaczenia (np. Agata - „dobra”, Barbara - „dzika”, Irena - „pokój”, Paweł - „mały”)

${ }^{2}$ Zob. I. Grześczak, Casus Pascudeus. Dlaczego nie lubimy uczyć się łaciny?, w: Wszystkie drogi prowadza do łaciny, red. I. Grześczak, Warszawa 2015, s. 26.

${ }_{3}$ Podane w tym miejscu oraz poniżej przykłady zapożyczeń z języka łacińskiego oraz greckiego podano w oparciu: Słownik grecko-polski, t. 1-2, red. O. Jurewicz, Warszawa 2000-2001; Słownik łacińsko-polski, t. 1-5, red. M. Plezia, Warszawa 1998-1999; Słownik wyrazów obcych PWN, red. E. Sobol, Warszawa 2002. 
Wyrazy łacińskiego pochodzenia stanowią bowiem ok. 10 proc. polskiego słownictwa i wraz z greckimi tworzą najliczniejszą grupę zapożyczeń w języku polskim ${ }^{4}$. Przy czym niewątpliwie łatwiej jest nam zrozumieć terminy wzięte z łaciny, m.in.: actio („akcja”), aversio („awersja”), caput („głowa, rozdział”, stąd „dekapitacja” i „akapit”), color („kolor”), decretum („dekret”), degradatio („degradacja”), documentum („dokument”), fenestra („okno”, stąd „defenestracja”), forma („forma”), fragmentum („fragment”), lingua („język”, stąd „lingwistyka”), locus („miejsce”, stąd polskie słowo „lokalizacja”), occasio („okazja”), patria („ojczyzna”, stąd „patriota”), senatus („senat”), stipendium („żołd”), studium („nauka”), tractatus („traktat”). Wyrażenia te są nam bliższe niż zapożyczenia pochodzące z języka greckiego. Trudniej nam bowiem greckie słowo hodos („droga”) połączyć z „chodzeniem”, a „kalafior” z przymiotnikiem kallos („piękny”) czy „hipopotama” z „rzecznym koniem” (hippos - „kon'” + potamos - „rzeka”), mimo że wiemy, co to zawody hippiczne lub hippoterapia. Podobnie niełatwo w nazwie Lwowa wyszukać „lwa” i „miasto” (łac. Leopolis z gr. leon - „lew” i polis - „miasto”) lub w słowie „ksenofobia” wyróżnić gr. ksenos - „obcy” i phobos - „strach”.

Używając terminów: „agroturystyka”, „barbarzyńca”, „celebryta”, „,insulina”, „inteligencja”, „moneta”, „poganin”, „presja”, „reklama” czy „wirtualny”, pamiętajmy o ich łacińskim pochodzeniu. Bowiem ager to "ziemia uprawna”, stąd choćby polska „agroturystyka” czy „gospodarstwo agroturystyczne”; "celebryta” wywodzi się od celeber - „słynny”; ,insulina” zaś od insula - „wyspa” (organy w trzustce, tzw. wysepki Langerhansa); intelligo to „pojmować” (stąd m.in. „inteligencja”); „moneta" pochodzi od przydomka Junony Upominającej, w której świątyni znajdowała się mennica; paganus to „wieśniak”, czyli „człowiek mieszkający z dala od cywilizacji chrześcijańskiej”; premo, premere, pressi, pressum oznacza „uciskać” (stąd „presja”); zaś reclamare - „głośno krzyczeć”, a „wirtualny” bierze się od virtualis - „skuteczny, mogący zaistnieć”, et cetera (czyli ,i tak dalej”).

${ }^{4}$ Zob. D. Sutkowska, Nie ma polszczyzny bez łaciny, w: Wszystkie drogi prowadza do łaciny, dz. cyt., s. 31 . 


\section{Bogactwo słowotwórstwa}

Wiele słów tworzymy, używając klasycznych przedrostków, m.in.:

- maksi- (np. „maksymalny”),

- mini- (np. „minimalny”),

- super- (np. „superman”),

- anty- (np. ,antydatowany”),

- kontra- (np. „kontrowersyjny”),

- hiper- (np. „hiperinflacja”),

- poli (np. „poligamia”),

- de-(np. „dekompresja”),

- amfi- (np., ,amfilada”).

A bez przyimka pro trudno wyobrazić sobie nazwy wielu instytucji i stowarzyszeń, m.in. Pro Fide, Rege et Lege („Za Wiarę, Króla i Prawo”).

\section{Sententiae Latinae}

Z pewnością znamy i używamy wielu łacińskich zwrotów, exempli gratia: a posteriori - „Z następstw”; a priori - „Z założenia”; ad acta - „do akt”; ad hoc - „od razu, bez przygotowania”; alibi - „w innym miejscu”; alias - „Zwany”; anno Domini - „roku Pańskiego”; bene merenti - „dobrze zasłużonemu”; corpus delicti - „dowód rzeczowy”; ecce homo - „oto człowiek”; in flagranti - „na gorącym uczynku”; liberum veto - „wolne, nie pozwalam”; licentia poetica - „wolność poetycka”; non notus (NN) „nieznany”; notabene - „zwróć uwagę”; persona grata - „osoba mile widziana”; quo vadis - „dokąd idziesz”; status quo - „obecny stan rzeczy”; tabula rasa - „czysta tablica”; verte - „odwróć”; virtuti militari - „za męstwo na polu bitewnym" .

${ }^{5}$ Przytoczone w tym rozdziale sentencje i powiedzenia łacińskie zaczerpnięto z: Aurea dicta. Stynne łacińskie sentencje, przysłowia i powiedzenia, red. S. Kalinkowski, Warszawa 1997; Dicta. Zbiór łacińskich sentencji, przysłów, zwrotów, powiedzeń, red. C. Michalunio, Kraków 2004. 
Niemniej znajomość sentencji łacińskich pomaga nam w życiu, choć nie zawsze zdajemy sobie sprawę z ich klasycznego pochodzenia, m.in.: amicus certus in re incerta cernitur - "prawdziwego przyjaciela poznaje się w biedzie”; carpe diem - „chwytaj dzień”; cogito ergo sum - „myślę, więc jestem”; dura lex, sed lex - „twarde prawo, ale prawo”; errare humanum est - „błądzić jest rzeczą ludzką”; igorantia iuris nocet - „nieznajomość prawa szkodzi”; manus manum lavat - „ręka rękę myje”; mors parcit nulli - „śmierć nikogo nie oszczędza”; non omnis moriar - „nie wszystek umrę”; omne principium difficile - „każdy początek jest trudny”; veni, vidi, vici - „przybyłem, zobaczyłem, zwyciężyłem”.

Bardzo ubogacają naszą cywilizację także klasyczne zwroty sięgające do antycznej historii czy mitologii, np.: „kości zostały rzucone”, „przekroczyć Rubikon”, „puszka Pandory”.

\section{Język łaciński jako fundament języków europejskich}

Z łaciny narodziły się m.in. języki włoski, francuski, hiszpański, rumuński, portugalski, ale wybrzmiewa ona poprzez liczne zapożyczenia czy struktury gramatyczne również w mowie angielskiej i niemieckiej ${ }^{6}$.

Alfabet łaciński - przejęty przez Rzymian prawdopodobnie od Etrusków - przyjęty został w wielu krajach europejskich, ale znakami łacińskimi posługują się również mieszkańcy obu Ameryk, Australii, Turcji, Indonezji, Malezji oraz wiele ludów afrykańskich ${ }^{7}$. Zresztą już sam termin „alfabet” powstał od dwóch pierwszych liter alfabetu greckiego a (alfa) i $\beta$ (beta).

Ogromna część literatury starożytnej ocalała dzięki pracy kopistów, a oryginalne napisy możemy odczytać dzięki manuskryptom (łac. manus - „ręka” + łac. scriptum - „pismo”). Zaś wielkie litery alfabetu łacińskiego (tak zwaną majuskułę) oglądamy codziennie na klawiaturach naszych komputerów.

\footnotetext{
${ }^{6}$ Zob. M. Herman, O łacinie tylko dobrze..., dz. cyt., s. 35-67.

7 Zob. M. Herman, O łacinie tylko dobrze..., dz. cyt., s. 79.
} 


\section{Języki łaciński i grecki jako fundament cywilizacji europejskiej - dominujące obszary}

Z kultury starożytnej zaczerpnęliśmy kalendarz (już sama nazwa pochodzi od terminu Kalendae, oznaczającego w rzymskim systemie mierzenia czasu pierwszy dzień każdego miesiąca), nazwy tygodni i miesięcy. Początkowo rzymski rok kalendarzowy zaczynał się 1 marca, co potwierdzają liczebnikowe nazwy miesięcy: September, October, November i December (tzn. miesiąc siódmy, ósmy, dziewiąty i dziesiąty). Zaś kalendarz wprowadzony przez Juliusza Cezara w 45 roku a.Ch.n. (ante Christum natum - „przed narodzeniem Chrystusa”), po niewielkiej modyfikacji dokonanej w 1582 roku na mocy bulli papieża Grzegorza XIII, obowiązuje do dzisiaj ${ }^{8}$.

Z greki i łaciny wywodzi się również wiele terminów z zakresu szkolnictwa. Zapożyczyliśmy sam wyraz „szkoła” (z łac. schola i gr. schole), a także nazwy szkół średnich i wyższych: „gimnazjum” (gr. gimnazjon), „liceum” (od Lykeionu Arystotelesa), „akademia” (od Akademii Platona), „uniwersytet” (łac. universitas, z tym że nazwa ta powstała w średniowieczu ze zwrotu: universitas magistrorum et scholarium, tj. „ogół nauczycieli i studentów, tworzących daną szkołę”), „politechnika” (gr. poli- technia-, czyli „umiejętność w zakresie wielu sztuk”). Również większość nauczanych przedmiotów wzięła swe nazwy z języków klasycznych, np. „arytmetyka” (z gr. arithmos - „liczba”), „biologia” (gr. bios - „życie” + gr. logos - „nauka”), „fizyka” (gr. physike - „wiedza o przyrodzie”), „geometria” (gr. geo-metria - „mierzenie ziemi”), „gramatyka” (gr. gramma - „litera”), „informatyka” (łac. informare - „przedstawiać”, ,informować”), „literatura” (łac. litterae - „litery”, „literatura”), „matematyka” (gr. mathema „poznanie”), „ortografia” (gr. orthos - „prosty” + gr. graphe - „pismo”), „propedeutyka” (gr. propedeuein - „uczyć od podstaw”).

Językiem wykładowym średniowiecznych uczelni była łacina. Łacińskość uniwersytetu poświadczają również używane po dzień dzisiejszy słowa: decanus - „dziekan”, doctor - „doktor”, facultas - „fakultet, wydział”, index - „wykaz”, magister - „magister”, profesor - „profesor”,

\footnotetext{
${ }^{8}$ Zob. J. Wikarjak, Gramatyka opisowa języka łacińskiego, Warszawa 1997, s. 156.
} 
rector - „rektor”, semestris - „semestr”. Greckie i łacińskie terminy występują również w nazwach dziedzin naukowych, takich jak archeologia (nazwa od gr. arche - „początek”), astronomia (m.in. już sama „astronomia” pochodzi od łac. astrum i gr. astron - „gwiazda”, ,atmosfera” od gr. atmos - „para wodna” + gr. sphaira - „kula”, „kosmologia” z gr. kosmos - „świat”,), filozofia (m.in. już sama „filozofia” pochodzi od gr. phileo - „miłuję" + gr. sophia - „mądrość”, „metafizyka” z gr. meta ta physi$c a$ - „co następuje po fizyce”, „ontologia” z gr. on, ontos - „byt”), historia (m.in. z gr. historicos - „badający dzieje”, „archiwum” z łac. archivum i gr. archeion - „siedziba urzędu”), medycyna (m.in. ,apteka” z gr. apotheke - „skład”, „dentysta” z łac. dens - „ząb”, „kardiolog” z gr. kardia - „serce”, „onkolog” z gr. onkos - „gruda”, „pediatra” z gr. pais, paidos - „dziecko”, „recepta” z łac. praeceptum - „przepis”, „stomatolog” z gr. stoma - „usta”), teologia (m.in. nazwa „teologia” od gr. theos - „bóg”, „eschatologia” od gr. eschatos - „ostateczny”, „liturgia” od gr. leitourgia „służba publiczna”), sztuka i retoryka (m.in. nazwa „retoryka” od gr. rhetorike (techne) - „(sztuka) retoryki”, „metafora” od gr. metaphora - „przeniesienie”, „muzyka” od łac. musica i gr. mousike - „sztuka śpiewu i gry na instrumentach”, „ornament” od łac. ornamentum). Również w bardziej nowoczesnych dziedzinach nauki wykorzystuje się terminologię mającą klasyczny rodowód, m.in.: "automat” od gr. automatos - „samoczynny”, „automobil” z gr. autos - „sam” + łac. mobilis - „ruchomy”, „detonator” od lac. detonare - „grzmieć”, ,helikopter” od gr. helikos - „skręcony” + gr. pteron - „skrzydło”, „komputer” od łac. computare - „liczyć”, „kserokopia” od gr. kseros - „suchy” + łac. copia - „wielka ilość”.

Łacina wciąż pozostaje oficjalnym językiem państwa watykańskiego. Do dzisiaj też ważne dokumenty kościelne wydaje się w tymże języku, a Kościół nolens volens („chcąc nie chcąc”) stoi na straży antycznej tradycji. Stąd wiele terminów kościelnych wywodzi się z języków klasycznych, m.in. „adwent” od łac. adventus - „przybycie”, „apostoł” od łac. apostolus i gr. apostolos - „poseł”, „diakon” od łac. diaconus i gr. diakonos - „sługa”, „eklezjologia” od łac. ecclesia - „kościół” i z gr. ekklesia - „zgromadzenie”, „eucharystia” od łac. eucharistia i gr. eucharistia - „dziękczynienie”, „ewangelia” od łac. evangelium i gr. eu- angelion - „dobra nowina”, „komunia” od łac. communio i gr. koinonia - „wspólnota”, „prezbiter” od 
łac. prezbiter i gr. presbytes - „starzec”, „profeta” od łac. propheta i gr. prophetes - „prorok”). Język łaciński pozostaje również językiem liturgii Kościoła, gdyż niejednokrotnie podczas celebracji nadal padają słowa: oremus - „módlmy się," mea culpa - „moja wina”, gloria in excelsis - „chwała na wysokości”, via crucis - „droga krzyżowa”, Mater Dolorosa - „Matka Bolesna”. Zaś ogłoszenie nowo wybranej głowy Kościoła katolickiego następuje przez wypowiedzenie łacińskiej formuły: Annuntio vobis gaudium magnum, habemus Papam - „ogłaszam wam radość wielką, mamy papieża”. Świadectwem opisanego wyżej stanu rzeczy jest fakt, iż w 2012 roku papież Benedykt XVI wydał list apostolski Latina Lingua, na mocy którego ustanowiono Papieską Akademię Języka i Kultury Łacińskiej'.

Wreszcie tradycja pozostawiła nam wiele skrótów łacińskich związanych z religijną sferą życia. Te najbardziej znane to: „BMV” (Beata Virgo Maria - „Błogosławiona Dziewica Maryja”), „CMB” (Christus mansionem benedicat - „Niech Chrystus błogosławi temu domowi”), „DOM” (Deo optimo maximo - „Bogu najlepszemu, największemu”), „IHS” (Iesus hominum/hominis salvator - „Jezus Zbawca ludzi/człowieka”), „INRI” (Iesus Nasarenus Rex Iudaeorum - „Jezus Nazareńczyk Król Żydowski”), „RIP” ( Requiescat/requiesce in pace - „Niech spoczywa/spoczywaj w pokoju”).

\section{Status quo}

Z pewnością z nauczaniem języków klasycznych w Polsce nie jest dobrze, co potwierdziły wnioski z konferencji Kryzys nauczania łaciny kryzys kultury, która odbyła się 10 maja 2016 roku w krakowskiej siedzibie Polskiej Akademii Umiejętności. Faktycznie bowiem liczba polskich studentów uczących się języków starożytnych jest niewspółmierna do liczby ich kolegów z krajów zachodnich ${ }^{10}$. Nie możemy nawet marzyć o tym, żeby pozycja języka łacińskiego była tak mocna jak w Niemczech, gdzie nastąpił - jak pisze Wilfried Stroh - powrót do zainteresowania

\footnotetext{
9 Zob. M. Herman, O łacinie tylko dobrze..., dz. cyt., s. 117-119.

10 Zob. S. Stabryła, Polska Akademia Umiejętności w obronie łaciny, „Arkana” 2016 nr 4 (130), s. 143.
} 
starożytnością ${ }^{11}$. W krajach Europy zachodniej bardziej, aniżeli ma to miejsce w Polsce, podkreśla się znaczenie języków klasycznych i znajomość antycznej kultury. Wyrazem takiego stanu rzeczy jest mnogość zachodnich podręczników do nauki języka łacińskiego, w tym również przeznaczonych dla dzieci (np. ang. Minimus ${ }^{12}$ ), publikacji łacińskich wersji dzieł literatury popularnej (np. A. A. Milne, Winnie Ille Pu, wyd. 1991; A. Saint-Exupery, Regulus, wyd. 2001; J. K. Rowling, Harrius Potter et Philosophi Lapis, wyd. 2003; L. Carrol, Alicia in Terra Mirabili, wyd. 2011), czasopism (ang. „Adulescens”, belg. „Melissa”, niem. „Vox Latina”) czy nawet puzzli (np. In vino veritas. Das Lateinische Weischeitenspiel Anaconda).

Nowe technologie przynoszą lektorom języków klasycznych niespotykane dotychczas możliwości ${ }^{13}$. Oto bowiem w internecie dostępne są liczne piosenki w języku łacińskim czy krótkie filmiki nawiązujące do antycznego kręgu kulturowego. Łacina pojawiła się w Pasji Mela Gibsona oraz w Żywocie Briana, przygotowanym przez wykonawców z grupy Monty Pythona. Coraz popularniejsze stają się także czaty łacińskie (np. greges garrulorum), zaś radio fińskie emituje wiadomości w języku starożytnych Rzymian (www.eu2006.fi). Organizowane są wreszcie kursy łaciny żywej (np. na Uniwersytecie Adama Mickiewicza w Poznaniu czy krakowskim Ignatianum ${ }^{14}$ ) oraz spotkania propagujące kulturę antyczną ${ }^{15}$.

${ }_{11}$ Zob. W. Stroh, Łacina umarła, niech żyje łacina! Mała historia wielkiego języka, Poznań 2013, s. 292.

${ }^{12}$ Na rodzimym gruncie zbliżoną publikacją jest książka Lecha Kwiecińskiego, Dar Rzymianina, czyli lingua Latina. Krok pierwszy - gradus primus, Warszawa 2006.

${ }_{13}$ Podczas konferencji dydaktyczno-naukowej Specyficzne potrzeby studentów szkót wyższych a nauczanie języków obcych: kierunki rozwoju, nowe wyzwania, rekomendacje (Wrocław, 15-17 września 2016) Bogusława Frontczak z Uniwersytetu Papieskiego Jana Pawła II w Krakowie przedstawiła film animowany o porwaniu królewny, za pomocą którego można wprowadzać III deklinację łacińską. Zob. A. Czura, E. Jankowska, M. Jedynak, Specyficzne potrzeby studentów szkół wyższych a nauczanie języków obcych: kierunki rozwoju, nowe wyzwania, rekomendacje. Księga abstraktów, Wrocław 2016, s. 26.

${ }_{14}$ Zob. Kurs żywej łaciny, https://ifk.amu.edu.pl/dla-szko/dla-szkol/kursy-j-lacinskiego (10.11.2016); Łacina żywa, łacina wokół nas, http://www.ignatianum.edu.pl/projekty/ lacina-zywa--lacina-wokol-nas (10.11.2016).

1518 stycznia 2016 roku na Uniwersytecie Papieskim Jana Pawła II w Krakowie zorganizowano wieczór poezji łacińskiej zakończony sympozjonem - tradycyjną ucztą, na 


\section{Zakończenie}

Powyższe rozważania wypada zakończyć apelem: Pamiętajmy o naszych korzeniach! Korzystajmy ze zgromadzonej i sprawdzonej przez przodków wiedzy, wspólnego kodu będącego podstawą naszej cywilizacji! Uczmy się języków klasycznych, bo choć może nie uratują nam one życia jak przebranemu za chłopa Zagłobie, który krzyczał: „Jam szlachcic. Loquor Latine!”16, z pewnością bardzo je ubarwią.

\section{Bibliografia}

Aurea dicta. Stynne łacińskie sentencje, przysłowia i powiedzenia, red. S. Kalinkowski, Warszawa 1997.

Bulak J., Żywczak D., Amor, amicitia et... coena!, „Vita Academica” $2016 \mathrm{nr} 2$ (87), s. 23n.

Czura A., Jankowska E., Jedynak M., Specyficzne potrzeby studentów szkół wyższych a nauczanie języków obcych: kierunki rozwoju, nowe wyzwania, rekomendacje. Księga abstraktów, Wrocław 2016.

Dicta. Zbiór łacińskich sentencji, przystów, zwrotów, powiedzeń, red. C. Michalunio, Kraków 2004.

Grześczak I., Casus Pascudeus. Dlaczego nie lubimy uczyć się łaciny?, w: Wszystkie drogi prowadza do łaciny, red. I. Grześczak, Warszawa 2015, s. 13-28.

Herman M., O łacinie tylko dobrze. De lingua Latina nil nisi bene. Język łaciński i grecko-łacińskie dziedzictwo kulturowe we współczesnej Europie, Kraków 2014.

Słownik grecko-polski, t. 1-2, red. O. Jurewicz, Warszawa 2000-2001.

Stownik łacińsko- polski, t. 1-5, red. M. Plezia, Warszawa 1998-1999.

Stownik wyrazów obcych PWN, red. E. Sobol, Warszawa 2002.

której skosztować można było starożytnych przysmaków, przygotowanych według przepisów z książki H. Szymanderskiej, Kuchnia stara jak świat, Warszawa 2003. Zob. J. Bulak, D. Żywczak, Amor, amicitia et... coena!, „Vita Academica” $2016 \mathrm{nr} 2$ (87), s. 23n.

16 H. Sienkiewicz, Ogniem i mieczem, Warszawa 1991, s. 238 (t. 1, rozdz. XXVIII). Tłumaczenie autorki: „Jestem szlachcicem. Mówię po łacinie”. 
Stabryła S., Polska Akademia Umiejętności w obronie łaciny, „Arkana” 2016 nr 4 (130), s. 142-145.

Stroh W., Łacina umarła, niech żyje łacina! Mała historia wielkiego języka, Poznań 2013.

Sutkowska D., Nie ma polszczyzny bez łaciny, w: Wszystkie drogi prowadza do łaciny, red. I. Grześczak, Warszawa 2015, s. 29-44.

Wikarjak J., Gramatyka opisowa języka łacińskiego, Warszawa 1997.

\section{Netografia}

Kurs żywej łaciny, https://ifk.amu.edu.pl/dla-szko/dla-szkol/kursy-j-lacinskiego (10.11.2016).

Łacina żywa, łacina wokół nas, http://www.ignatianum.edu.pl/projekty/lacina-zywa--lacina-wokol-nas (10.11.2016).

\section{Abstract}

Classical languages constitute the foundation of our civilisation. Studying them can help you improve the ability to express yourself in your native language more clearly, it can facilitate the process of foreign language learning, and it also helps you understand your own cultural heritage better.

Słowa kluczowe: języki klasyczne, język grecki, język łaciński

Keywords: classical languages, Ancient Greek, Latin 